\title{
Effectiveness of omalizumab in a patient with a life-threatening episode of bronchospasm and larynx angioedema after exposure to house dust
}

\author{
Izabela Kupryś-Lipińska, Paulina Korczyńska, Damian Tworek, Piotr Kuna
}

Department of Internal Medicine, Asthma and Allergy, Norbert Barlicki Memorial University Hospital No. 1, Medical University of Lodz, Poland

Head of Department: Piotr Kuna MD, PhD

Postep Derm Alergol 2014, XXXI, 1: 39-44 DOI: 10.5114/pdia.2014.40659

\begin{abstract}
Omalizumab is a monoclonal antibody against IgE, nowadays approved for the treatment of persistent severe (EU) or moderate-to severe (USA) IgE-mediated asthma but there is also some evidence (case reports and four published clinical trials) on the effectiveness of this medication in urticaria and angioedema. The case of a 42 -year-old woman suffering from severe allergic asthma and severe chronic urticaria with concomitant angioedema is presented in the article. She had a life-threatening episode of bronchospasm and larynx edema after exposure to house dust recorded in her medical history. The patient did not respond to standard therapy. The improvement in asthma control and remission of chronic urticaria and angioedema was achieved after introducing the therapy with omalizumab.
\end{abstract}

Key words: severe asthma, chronic urticaria, life-threatening angioedema, omalizumab.

Omalizumab is a monoclonal antibody against IgE, approved for the treatment of persistent severe (EU) or moderate-to severe (USA) IgE-mediated asthma. It is very effective in reducing asthma exacerbations as well as patients' hospitalizations and emergency visits due to exacerbations. Moreover, it decreases severity and frequency of asthma symptoms and improves the quality of life.

Omalizumab is administered subcutaneously and thus it shows a more extensive systemic antiallergic effect than the antiasthmatic action. Some clinical trials and case reports which have been published so far show its effectiveness inter alia in allergic rhinitis, nasal polyps, severe atopic dermatitis, urticaria, angioedema, food allergy, anaphylaxis, and mastocytosis [1].

This article presents a case report of a patient with the history of a life-threatening episode of bronchospasm and larynx edema after exposure to house dust.

At present, the patient is a 42-year-old woman suffering from severe allergic asthma and severe chronic urticaria with concomitant angioedema. She is allergic to tree, grass and weed pollens, house dust mites and cat dander. Apart from asthma and urticaria she has developed allergic rhinitis, nasal polyps, oral allergy syndrome (apples, carrots, pears, cherries, strawberries, celeriac, walnuts), drug allergy or intolerance (antibiotics, local anesthetics, proton pump inhibitor (PPI), non-steroid anti-inflammatory drugs (NSAID), some corticosteroids (CS)), and chronic gastritis. She works as a teacher in a primary school but due to the allergy she has been temporary unable to work since asthma and urticaria became severe.

The patient has been suffering from allergy since her childhood. Asthma and allergic rhinitis started at the age of 7 . At the beginning, allergy symptoms were seasonal, however when she was 26 years old they became perennial with seasonal exacerbations. At the same time nasal polyps were diagnosed and the patient underwent polypectomy. Two years earlier, oral allergy syndrome had appeared.

In 2002, the woman started allergen immunotherapy with subcutaneous vaccine containing pollen allergens but had to interrupt it due to the suspicion of myocarditis in the course of viral respiratory tract infection.

In 2004, when the patient was 33 years old, asthma became severe and uncontrolled with everyday asthma symptoms despite the maximal antiasthmatic therapy with continuous oral steroids treatment (step 5 acc. to GINA recommendations). She experienced frequent asthma exacerbations due to recurrent viral infections and exposure to allergens, and was hospitalized. Since 2004, recurrent episodes of urticaria and angioedema have occurred, although the first episode of urticaria was at

Address for correspondence: Izabela Kupryś-Lipińska MD, PhD, Department of Internal Medicine, Asthma and Allergy, Norbert Barlicki Memorial University Hospital No. 1, Medical University of Lodz, 22 Kopcińskiego St, 90-153 Lodz, Poland, phone: +48 426776939, fax: +48 4267769 43, e-mail: izabela.kuprys-lipinska@wp.pl

Received: 7.01.2013, accepted: 13.01.2014. 

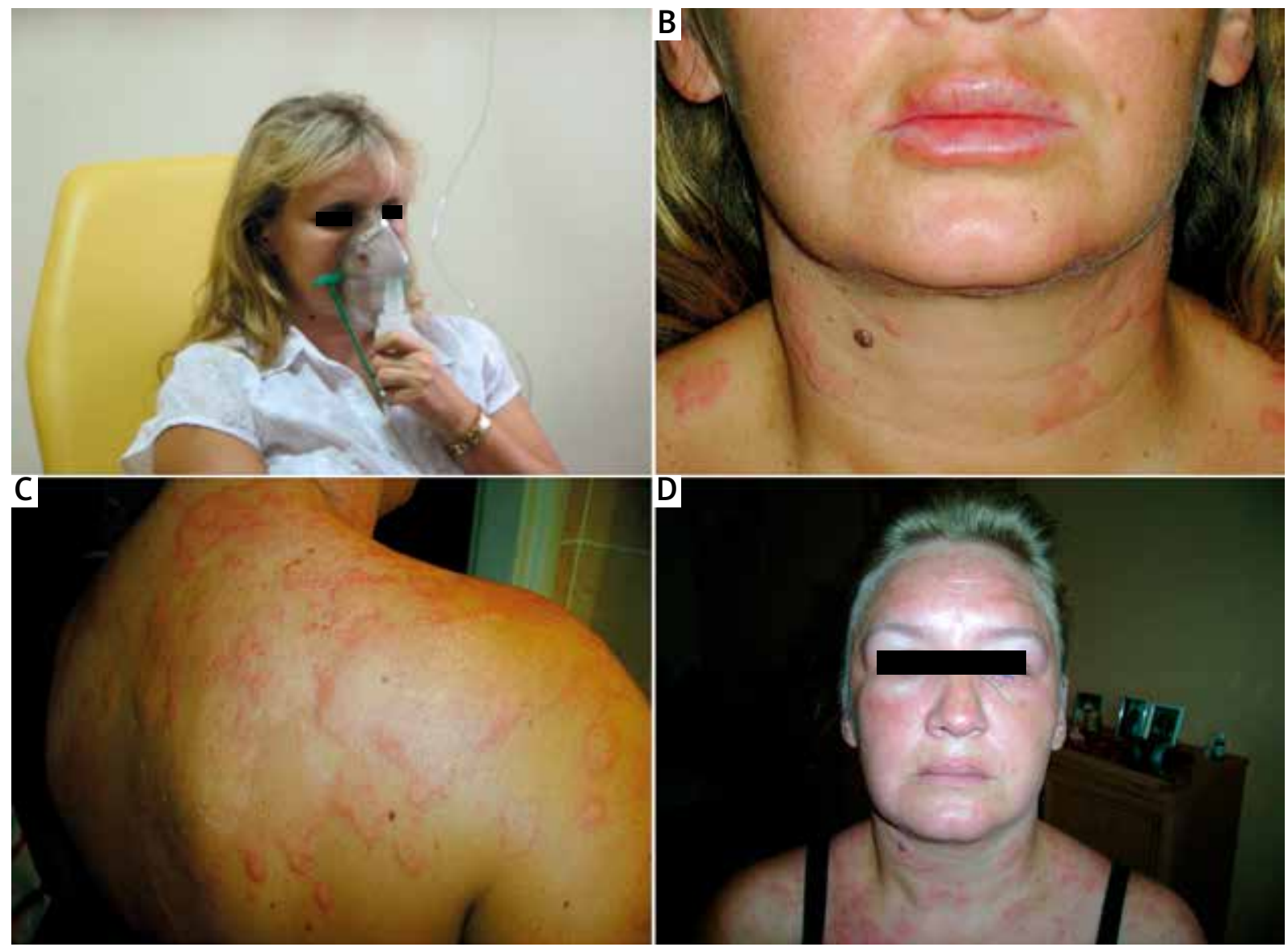

Figure 1 A-D. Allergic reaction after exposure to house dust

the age of 7. An attempt to apply cyclosporine therapy appeared to be ineffective as well as long-acting intramuscular steroids.

In 2006, the patient's health dramatically deteriorated: she was administered up to $60 \mathrm{mg}$ of prednisolone per day besides 1000 ug fluticasone per day, formoterol and montelukast. Additionally, she needed intravenous steroids. Severe attacks of asthma and edema of larynx occurred due to the exposure to house dust. In consequence, she had to be treated with epinephrine and hospitalized (Figures 1 A-D).

She underwent a thorough allergological testing and medical examination. Skin-prick tests revealed positive reactions to trees, grass and weed pollens, dust mites,

Table 1. Diagnostic procedures

\begin{tabular}{|c|c|}
\hline Total IgE level - $630 \mathrm{IU} / \mathrm{ml}$ & Compliment C3 and C4 levels reduced (in acute phase) \\
\hline Specific lgE - above class 2 for mites and animal dander & $\uparrow$ Total IgG (subclasses within normal limits), IgM and IgA normal \\
\hline $\begin{array}{l}\text { Skin prick tests positive to house dust mites, cat, trees, grass, } \\
\text { weeds }\end{array}$ & ANA and ANCA negative \\
\hline Spirometry - severe obturation & Thyroid hormones TSH and FT4 - normal range \\
\hline Morphology normal except eosinophilia > 1500 cells $/$ mm³ $^{3}$ & Test for parasites - negative \\
\hline X-ray of thorax - normal & $\begin{array}{l}\text { Marrow biopsy - without evidence of neoplastic growth, } \\
\text { eosinophilia }\end{array}$ \\
\hline CT of lung - normal & Bronchoscopy - chronic bronchitis \\
\hline Cardiac USG - normal & $\begin{array}{l}\text { Gastroscopy - non active chronic gastritis, specific IgG and urease } \\
\text { test - Helicobacter pylori }(+) \text {; incomplete eradication due to } \\
\text { angioedema to PPI }\end{array}$ \\
\hline
\end{tabular}


cat dander, nuts (hazel and walnut), kiwi allergens, the total lgE level was $631 \mathrm{lU} / \mathrm{ml}$ and specific IgE levels were greater than class 2.0 for mites mix and animal dander mix. The patient was comprehensively diagnosed (Table 1) due to high blood eosinophilia (over 1500 eosinophils/ $\mathrm{mm}^{3}$ ) but no signs of neoplastic proliferation of bone marrow and eosinophilic syndromes were detected.

In 2007, she started omalizumab therapy. The calculated dose of omalizumab based on the IgE level and weight initially was 375 mg every 2 weeks and was later modified due to weight change. Urticaria and angioedema disappeared within 1 month of therapy, and after 2 months, asthma control started to improve (Figure 2 A). The need for systemic corticosteroids decreased and asthma exacerbations rate significantly decreased (Figure 2 B). The blood eosinophil count normalized and lung functions improved. The patient's quality of life improved (Figure $2 \mathrm{~A}$ ) and she returned to work.

The therapy has been continued up to the present day with the sustained improvement (Figures $2 \mathrm{~A}$ and 2 B), but an interruption (up to 3 months due to administrative problems with reimbursement of therapy) in the treatment resulted in the loss of asthma control, recurrence of asthma exacerbations (within 8 weeks) as well as urticaria and angioedema episodes (within 4 weeks), and an increase in the need for corticosteroids.

Nowadays, the patient takes 450 mg of omalizumab every 2 weeks, feels well and works. As she takes medicine regularly, no urticaria and angioedema appear, asthma exacerbations due to viral infection or allergen

A

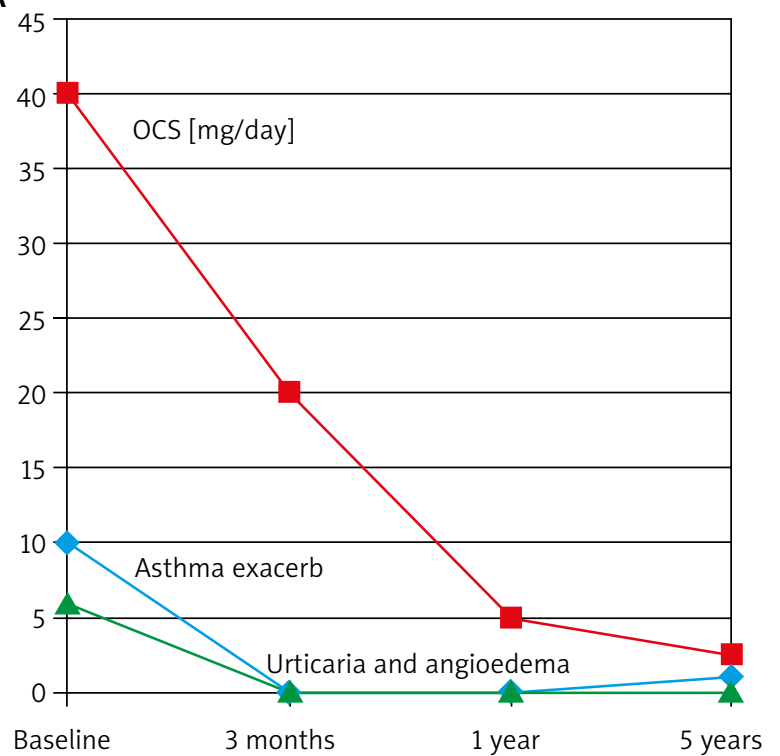

exposure do not exceed 2 episodes per year (usually 1 per year) and can be treated at home, the daily dose of oral corticosteroids has maintained between $2.5 \mathrm{mg}$ to $5 \mathrm{mg}$ of prednisolone. The patient needs to be treated continuously and any interruption in the treatment is a life-threatening condition due to the risk of severe bronchospasms and larynx edema.

The effectiveness of omalizumab in severe asthma has been proved in many clinical trials [2, 3], pooled [4] and meta-analysis [5, 6] as well as real-life reports [7-9]. The therapy improves asthma control, decreases the number of severe exacerbations and hospitalizations due to asthma exacerbations, enables to decrease the daily dose of systemic corticosteroids as well as improves asthma-related quality of life. This medication was approved for asthma treatment initially in Australia in 2002, then in the USA and Europe, in 2004 and 2005, respectively.

The evidence regarding the effectiveness of this drug in urticaria and angioedema is based on a few case reports and four clinical trials.

The first report on the effectiveness of omalizumab in urticaria comes from 2006 and was written by Boyce [10] who described the case of a girl suffering from moderate asthma and idiopathic cold urticaria with severe reactions despite therapy with $\mathrm{H}_{1}$ antagonists and cysteinyl leukotrienes receptor antagonist. Therapy with omalizumab (375 mg every 2 weeks) resulted in asthma control improvement and complete resolution of her urticaria and its associated manifestations.

B

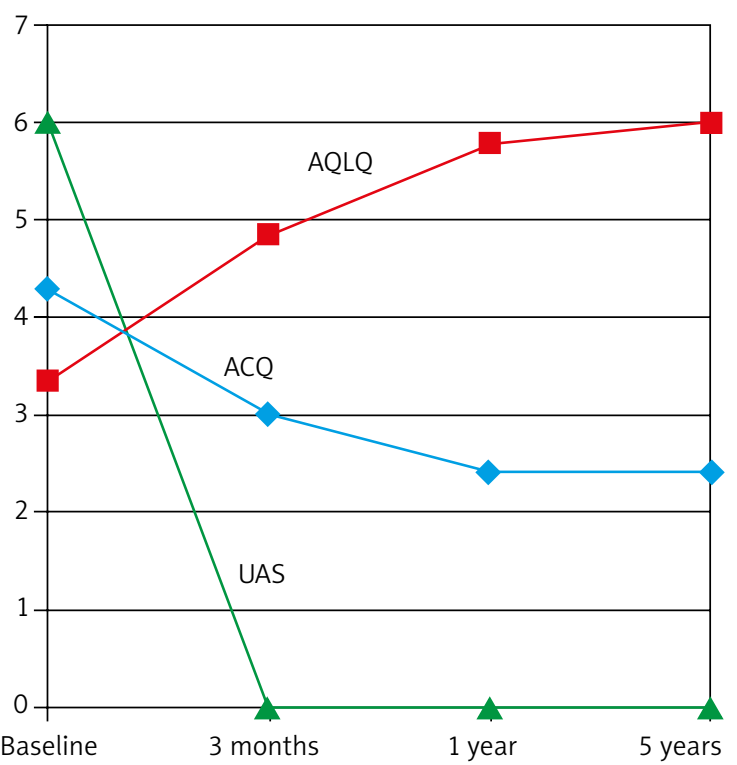

OCS - oral corticosteroids, ACQ - Asthma Control Questionnaire, AQLQ - Asthma Quality of Life Questionnaire, UAS - Urticaria Activity Score

Figure 2. Clinical effect of omalizumab on asthma exacerbation, urticaria/angioedema episodes, need for oral corticosteroids (A), asthma control, asthma-related quality of life and severity of urticaria (B) 
The first publication about effectiveness of this medication in angioedema appeared in 2007 and was prepared by Sands et al. [11]. They reported three cases of refractory idiopathic angioedema. All patients were men aged 50 to 65 years and experienced severe life-threatening larynx edema without urticaria eruption. Two of them had concomitant asthma, the remaining one - chronic obstructive pulmonary disease (COPD). They were all successfully treated with omalizumab (300 mg every 4 or 3 weeks or $375 \mathrm{mg}$ every 2 weeks, respectively) with immediate effect.

Maspero et al. [12] described a 12-year-old female who suffered from severe chronic autoimmune urticaria/angioedema. She had a poor response to the highest doses of combined therapy with 3 antihistamines, corticosteroids and antileukotrienes. After introducing omalizumab therapy (150 mg every 4 weeks acc. to the manufacturer's dosing table for asthma treatment), the patient became asymptomatic and had a negative autologous serum skin test result.

Korkmaz et al. [13] published a case of a 29-year-old man suffering from severe chronic urticaria and angioedema with unknown provoking factors, resistant to therapy with high-dose systemic corticosteroids and antihistamines, leukotriene antagonist, cyclosporine and antibiotics. Introducing therapy with omalizumab resulted in the complete remission of the chronic urticaria after 2 weeks.

Sánchez-Machín et al. [14] reported the case of a 35year-old woman with severe chronic urticaria and angioedema as well as concomitant allergic rhinoconjunctivitis and episodic allergic asthma. She was sensitized to mites. Her urticaria was poorly controlled with conventional treatments (antihistamines and oral corticosteroids). Cyclosporine at doses of $200 \mathrm{mg}$ per day initially showed good response, but after the dose reduction to $100 \mathrm{mg}$, symptoms relapsed. Omalizumab therapy (300 mg every 2 weeks acc. to the manufacturer's dosing table for asthma treatment) led to the relief of dramatic symptoms within $72 \mathrm{~h}$. The patient decided to discontinue the therapy and no exacerbation of her state occurred.

Up to now the reports on successful treatment with omalizumab in cholinergic [15], solar [16], delayed pressure [17], heat [18], dermographic [19] and chronic idiopathic [20] or autoimmune [21, 22] forms of urticaria were published.

Recently, the results of four clinical trials have been published. The first two papers were published in 2011, including one by Maurer et al. [23]. They showed the results of a multicenter, randomized, double-blind, placebo-controlled study on patients with autoimmune chronic urticaria with or without angioedema refractory to conventional treatment (X-QUISITE study). From 49 randomized patients (omalizumab, $n=27$; placebo, $n=22), 42$ completed the study. The active phase lasted for 24 weeks and the omalizumab dose was consistent with the approved asthma dosing table. At the end of the study, patients who received omalizumab demonstrated a greater reduction in the weekly urticaria activity score $(p=0.0089)$. Complete protection from wheal development was observed in 19 (70.4\%) patients in the omalizumab group compared with only 1 (4.5\%) patient in the placebo group. A similar effect was observed in the case of angioedema - complete absence of angioedema was observed in $77.8 \%$ of patients in the omalizumab group compared with only $36.4 \%$ in the placebo group. The therapy was well tolerated.

Just after the Maurer's publication, a paper by Saini [24] et al. was published. It was a prospective, double-blind, placebo-controlled, dose-ranging study investigating omalizumab in patients with chronic urticarial symptoms despite antihistamine therapy (MYSTIQUE study). Ninety patients were enrolled and randomized for the study to one of the four groups: 75,300 , or $600 \mathrm{mg}$ of omalizumab or placebo. All of them received one dose of the drug and were observed subsequently for 4 weeks. Both the 300-mg and the 600-mg omalizumab groups showed a greater improvement versus the placebo group in Weekly Urticaria Activity Score (UAS7). The effect of treatment was visible after 1 to 2 weeks. The effect of $75 \mathrm{mg}$ dose was small and statistically insignificant. There was no information about the number of subjects with angioedema and the effect of omalizumab therapy on this symptom. Omalizumab was well tolerated, and the incidence of adverse events was similar across treatment groups.

In 2013, the results of two studies were published. One was performed by Maurer et al. [25]. It was a multicenter, randomized, double-blind study evaluating the efficacy and safety of omalizumab in patients with moderate-to-severe chronic idiopathic urticaria, who remained symptomatic despite $\mathrm{H}_{1}$-antihistamine therapy (licensed doses). A total of 323 patients were randomly assigned to receive 12-week omalizumab therapy $(75 \mathrm{mg}$, $150 \mathrm{mg}$, or $300 \mathrm{mg}$ or placebo every 4 weeks) with a subsequent 16-week observation period. Angioedema was present during the week before randomization in $41 \%$ of patients. The therapy with omalizumab diminished clinical symptoms and signs of chronic idiopathic urticaria in a dose-dependent manner. The effect of $75 \mathrm{mg}$ dose did not differ from placebo, the maximal effect was achieved at the dose of $300 \mathrm{mg}$ for all measured parameters except for the difference in the number of angioedema-free days from week 4 to week 12 , which reached significance only in the $300 \mathrm{mg}$ group.

The most recent publication has been written by Kaplan et al. [26]. It is a study evaluating the safety and efficacy of 24 weeks of treatment with omalizumab in patients with persistent chronic idiopathic urticaria (CIU)/ chronic spontaneous urticaria (CSU) despite treatment with $\mathrm{H}_{1}$-antihistamines at up to 4 times of the approved 
dose plus $\mathrm{H}_{2}$-antihistamines, leukotriene receptor antagonists, or both (Glacial study). A total of 336 patients were randomized $3: 1$ to $300 \mathrm{mg}$ of omalizumab or placebo administered every 4 weeks for 24 weeks and subsequently observed for 16 weeks. The therapy with omalizumab was well tolerated and significantly reduced the signs and symptoms of CIU/CSU compared with placebo in all measured efficacy end points including an improvement in days free from angioedema. These significant improvements were sustained throughout the 24-week treatment period.

Urticaria is a heterogeneous group of diseases with a distinctive skin reaction pattern: urticarial skin lesions and/or angioedema elicited by various provoking factors [27-31]. The pathomechanism is not fully known. Our patient had chronic urticaria with concomitant angioedema and known (mite allergens, NSAID, PPI) and unknown triggers. The omalizumab dose was calculated acc. to the manufacturer's dosing table for asthma treatment since asthma was the first indication for that therapy and its effect on urticaria and angioedema was unknown at that time, however it appeared to be spectacular.

Omalizumab works by blocking free circulating IgE and inhibits their binding to the specific receptors. Omalizumab also down-regulates IgE receptors on the effector cells. Additionally, omalizumab has been shown to exert an anti-inflammatory effect by the impact on peripheral eosinophil and T-lymphocyte function. This way it decreases or even completely blocks allergic reaction and asthma symptoms [1]. But the mechanism by which it works in urticaria and angioedema is still unknown. Both IgE-related and alternative pathways have been postulated.

Irrespective of the mechanisms, omalizumab appeared to be effective in patients with the history of severe, life-threatening angioedema and its use should be considered in cases refractory to standard treatment. The effect of omalizumab in urticaria is dose dependent, the effective dose begins from $150 \mathrm{mg}$ every 4 weeks and is independent of the IgE level. The dose of omalizumab for patients suffering from urticaria with concomitant angioedema probably should be higher (minimum $300 \mathrm{mg}$ every 4 weeks) than for patients with urticaria alone.

\section{Acknowledgments}

The authors thank the patient for providing the photos and permission to publish them.

\section{References}

1. Kupryś-Lipińska I, Kuna P. Omalizumab, recombinant humanized monoclonal antibody anti-lgE: new fields of studies on the therapeutic indications. Pneumonol Alergol Pol 2009; 77: 43-51.
2. Humbert M, Beasley R, Ayres J, et al. Benefits of omalizumab as add-on therapy in patients with severe persistent asthma who are inadequately controlled despite best available therapy (GINA 2002 step 4 treatment): INNOVATE. Allergy 2005; 60: 309-16.

3. Norman G, Faria R, Paton F, et al. Omalizumab for the treatment of severe persistent allergic asthma: a systematic review and economic evaluation. Health Technol Assess 2013; 17: 1-342.

4. Walker S, Burch J, McKenna C, et al. Omalizumab for the treatment of severe persistent allergic asthma in children aged 6-11 years. Health Technol Assess 2011; 15 Suppl. 1: 13-21.

5. Walker S, Monteil M, Phelan K, et al. Anti-lgE for chronic asthma in adults and children. Cochrane Database Syst Rev 2006; 2: CD003559.

6. Bousquet J, Cabrera P, Berkman N, et al. The effect of treatment with omalizumab, an anti-IgE antibody, on asthma exacerbations and emergency medical visits in patients with severe persistent asthma. Allergy 2005; 60: 302-8.

7. Molimard M, de Blay F, Didier A, Le Gros V. Effectiveness of omalizumab (Xolair) in the first patients treated in real-life practice in France. Respir Med 2008; 102: 71-6.

8. Barnes N, Menzies-Gow A, Mansur AH, et al. Effectiveness of omalizumab in severe allergic asthma: a retrospective UK real-world study. J Asthma 2013; 50: 529-36.

9. Deschildre A, Marguet C, Salleron J, et al. Add-on omalizum$a b$ in children with severe allergic asthma: a 1-year real life survey. Eur Respir J 2013; 42: 1224-33.

10. Boyce JA. Successful treatment of cold-induced urticaria/ anaphylaxis with anti-lgE. J Allergy Clin Immunol 2006; 117: 1415-8.

11. Sands MF, Blume JW, Schwartz SA. Successful treatment of 3 patients with recurrent idiopathic angioedema with omalizumab. J Allergy Clin Immunol 2007; 120: 979-81.

12. Máspero JF, Parisi CA, De Gennaro M, et al. Chronic autoimmune urticaria: treatment with omalizumab. Arch Argent Pediatr 2009; 107: 452-6.

13. Korkmaz H, Eigelshoven S, Homey B. Omalizumab for therapy-resistant chronic urticaria with angioedema. Hautarzt 2010; 61: 828-31.

14. Sánchez-Machín I, Iglesias-Souto J, Franco A, et al. T cell activity in successful treatment of chronic urticaria with omalizumab. Clin Mol Allergy 2011; 9: 11.

15. Metz M, Bergmann P, Zuberbier T, Maurer M. Successful treatment of cholinergic urticaria with anti-immunoglobulin E therapy. Allergy 2008; 63: 247-9.

16. Güzelbey O, Ardelean E, Magerl M, et al. Successful treatment of solar urticaria with anti-immunoglobulin E therapy. Allergy 2008; 63: 1563-5.

17. Bindslev-Jensen C, Skov PS. Efficacy of omalizumab in delayed pressure urticaria: a case report. Allergy 2010; 65: 138-9.

18. Bullerkotte U, Wieczorek D, Kapp A, Wedi B. Effective treatment of refractory severe heat urticaria with omalizumab. Allergy 2010; 65: 931-2.

19. Krause K, Ardelean E, Kessler B, et al. Antihistamine-resistant urticariafactitia successfully treated with anti-immunoglobulin E therapy. Allergy 2010; 65: 1494-5.

20. Vestergaard C, Deleuran M. Two cases of severe refractory chronic idiopathic urticaria treated with omalizumab. Acta Derm Venereol 2010; 90: 443-4. 
21. Máspero JF, Parisi CA, De Gennaro M, et al. Chronic autoimmune urticaria: treatment with omalizumab. Arch Argent Pediatr 2009; 107: 452-6.

22. Al-Ahmad M. Omalizumab therapy in three patients with chronic autoimmune urticaria. Ann Saudi Med 2010; 30: 478-81.

23. Maurer M, Altrichter S, Bieber T, et al. Efficacy and safety of omalizumab in patients with chronic urticaria who exhibit IgE against thyroperoxidase. J Allergy Clin Immunol 2011; 128: 202-9.

24. Saini S, Rosen KE, Hsieh HJ, et al. A randomized, placebo-controlled, dose-ranging study of single-dose omalizumab in patients with $\mathrm{H} 1$-antihistamine-refractory chronic idiopathic urticaria. J Allergy Clin Immunol 2011; 128: 567-73.

25. Maurer M, Rosén K, Hsieh HJ, et al. Omalizumab for the treatment of chronic idiopathic or spontaneous urticaria. N Engl J Med 2013; 368: 924-35.

26. Kaplan AP, Joseph K, Maykut RJ, et al. Treatment of chronic autoimmune urticaria with omalizumab. J Allergy Clin Immunol 2008; 122: 569-73.

27. Zuberbier T, Asero R, Bindslev-Jensen C, et al. EAACI/ GA2LEN/EDF/WAO guideline: definition, classification and diagnosis of urticarial. Allergy 2009; 64: 1417-26.

28. Kołacińska-Flont M, Antczak-Marczak M, Pawłowski M, Kuna P. Anti-Helicobacter pylori IgG titre in patients with chronic idiopathic urticaria and the effect of Helicobacter pylori eradication on urticarial. Postep Derm Alergol 2012; 29: 8085.

29. Ucmak D, Akkurt M, Toprak G, et al. Determination of dermatology life quality index, and serum C-reactive protein and plasma interleukin- 6 levels in patients with chronic urticarial. Postep Derm Alergol 2013; 30: 146-51.

30. Gomutka K. Cold urticaria: a case report. Postep Derm Alergol 2012; 29: 60-2.

31. Brzeski Pt, Spatkowska M, Podbielska M, et al. The role of focal infections in the pathogenesis of psoriasis and chronic urticaria. Postep Derm Alergol 2013; 30: 77-84. 